\title{
Evaluation of Exhalation Valves
}

\section{YU-MEI KUO ${ }^{1}$, CHANE-YU LAI ${ }^{2}$, CHIH-CHIEH CHEN ${ }^{3}$, BO-HONG LU $^{3}$, SHENG-HSIU HUANG ${ }^{4}$ and CHUN-WAN CHEN ${ }^{4}$}

\author{
${ }^{1}$ Department of Occupational Safety and Health, Chung Hwa College of Medical Technology, \\ 89, Wen-Hwa 1st Street, Jen-Te Hsiang, Tainan Hsien, Taiwan 717; ${ }^{2}$ Department of Occupational \\ Safety and Hygiene, Chung Shan Medical University, 110, Section 1, Kan-Ko N. Road, Taichung, \\ Taiwan 402; ${ }^{3}$ Institute of Occupational Medicine and Industrial Hygiene, College of Public Health, \\ National Taiwan University, 1, Section 1, Ren-Ai Road, Taipei, Taiwan 100; ${ }^{4}$ Institute of \\ Occupational Safety and Health, Council of Labor Affairs, 99, Lane 407, Hengke Road, \\ Sijhih City, Taipei County, Taiwan 221
}

Received 25 October 2004; in final form 14 January 2005; published online 16 February 2005

\begin{abstract}
Certification tests currently employed by some industrialized nations to certify respirators require that when challenged with air flow at a constant suction head of $25 \mathrm{mmH}_{2} \mathrm{O}$, the leakage into the facepiece from the exhalation valve(s) should not exceed $30 \mathrm{ml} \mathrm{min}^{-1}$. However, the test alone might not reflect the leakage rate under different levels of vacuum. To study the characteristics of leakage through exhalation valves, a leakage meter was built to measure the leakage rate of four brands of exhalation valves. Seven valves of each brand were tested for leakage rate at pressure drops ranging from 15 to $45 \mathrm{mmH}_{2} \mathrm{O}$ (or extended to $75 \mathrm{mmH}_{2} \mathrm{O}$ for some valves). Two types of leaks, i.e. fiber insertion and arch dent on the valve seat, were used to investigate the effect of leak shape on the characteristic leak flow as a function of pressure drop. A leakage data point represented a mean value of five measurements. The results showed that the leakage rate could increase or decrease with increasing pressure drop inside the respirators, indicating that the current method of conducting leakage tests, at a constant suction head of $25 \mathrm{mmH}_{2} \mathrm{O}$, does not guarantee better protection than when the respirators are used at a lower suction head. Moreover, based on the sample valves tested in this study, it was found that valve leakage was mostly caused by defects in the valve seats. Both fiber-insertion and arch-dent leaks had either increasing or decreasing characteristic curves, depending on the size of the leak and the material of the valve membrane.
\end{abstract}

Keywords: exhalation valves; leakage rate; pressure drop

\section{INTRODUCTION}

Respirators are commonly used to protect workers from coming into contact with air contaminants, especially when engineering and work practice controls fail to reduce workers' exposure to acceptable levels. However, wearing a respirator often makes wearers feel uncomfortable due to the accumulation of water vapor and heat inside the respirators and the air resistance during exhalation. For certain highgrade air-purifying respirators, because of the high air resistance caused by the filter media, exhalation valves have been designed to permit minimal inward leakage of air contaminants during inhalation and to

\footnotetext{
*Author to whom correspondence should be addressed. Tel: +886 22393 8631; fax: +886 22321 5741; e-mail: ccchen@ntu.edu.tw
}

provide low air resistance during exhalation, in order to reduce the level of discomfort.

Respirators can provide adequate protection against exposure to toxic substances only when insignificant amounts of contaminants enter the respirator. In general, air contaminants may enter the respirator by three major routes, namely filter penetration, facial seal leakage and exhalation valve leakage, in the order of importance. If a respirator is properly donned and no exhalation valves are installed, filter penetration, which has been intensively studied by Chen et al. $(1992,1993)$ is the only route of inhalation exposure for the respirator wearer. According to the NIOSH/US filter test requirements, aerosol penetration through N95 facepieces and its equivalents can be as high as 5\%. Penetration through the facial seal leaks will become important when a higher protection factor is needed, because when more filter 
media are added to reduce the aerosol penetration by this route, the resulting high air resistance will force part of the air and the contaminants to find another route, e.g. the facial seal leakage (Hinds and Kraske, 1987; Chen and Willeke, 1992). Assuming that the filter has an efficiency of $100 \%$, a protection factor of 1000 means that $0.1 \%$ of air penetrates through the face seal leaks. For the same reason, the leakage through exhalation valves would become important if a high protection factor is needed (Bellin and Hinds, 1990; Nelson et al., 1992; Brosseau, 1998). In general, the leakage of a properly functioning exhalation valve may be low compared with the filter penetration and facial seal leakage. However, significant leakage might occur if the valve is malfunctioning due to defects in the valve membrane and/or the valve seat.

In general, exhalation valves are made up of three major components - a valve membrane, a seat and a cover. The valves (membranes) are usually made from natural or silicone rubber or neoprene. The seats of the tested valves are designed as a contoured peripheral base with a cross bracket, and the valve membrane is attached to the seat. The valve membrane sits against the base to block the valve hole during inspiration and lifts from the base due to the positive pressure established during expiration. The valve covers with different geometries provide protection to the delicate valve.

Certification tests currently employed by AS/NZS 1716-1994 (Australia) and 42CFR part 84 (USA) require that the leakage into new exhalation valves should not exceed $30 \mathrm{ml} \mathrm{min}^{-1}$ at a suction pressure of $25 \mathrm{mmH}_{2} \mathrm{O}$. Previous studies (Hinds and Kraske, 1987; Chen et al., 1993) have shown that this highpressure drop occurred only when HEPA grade respirators were used under heavy workload, i.e. breathing flow reaching $\sim 1001 \mathrm{~min}^{-1}$. As a result, it is logical to infer that, in the current regulation on exhalation valve performance, leakage rate from exhalation valves can be assumed to increase with increasing pressure drop across the respirators. However, this test alone might not reflect the leakage rate under different levels of vacuum. Therefore, one of the main objectives of this study was to investigate the leakage characteristics of exhalation valves as a function of the pressure drop. It is also of interest to investigate which component(s) of the valve, i.e. valve membrane or valve seat, is responsible for the leak.

\section{MATERIALS AND METHODS}

Four brands of exhalation valves were tested in the present study, with the code names E, M, S and W, as shown in Fig. 1. Of the four valves tested, valves E, $S$ and $\mathrm{W}$ had a similar design (mushroom style), whereas valve $\mathrm{M}$ had a completely different design from the other valves. Valve $\mathrm{M}$ was edge-pinned and
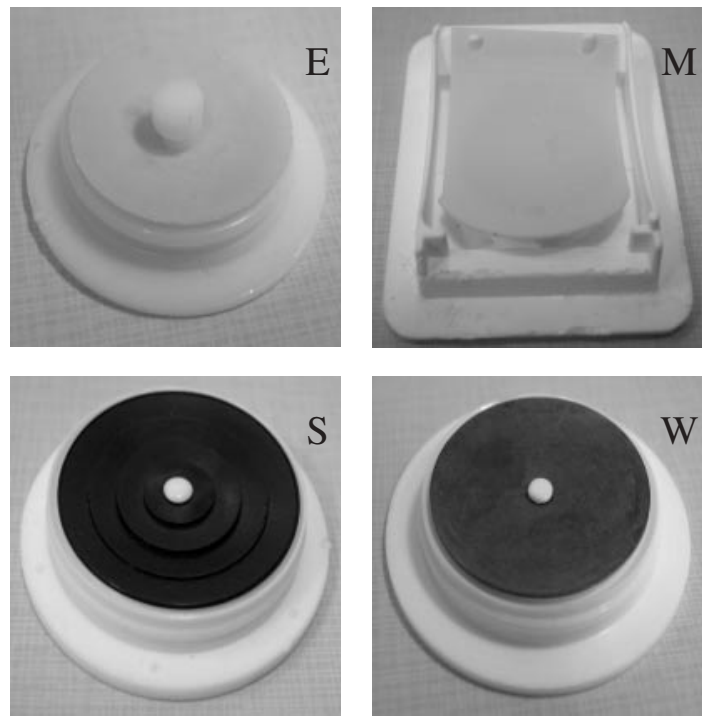

Fig. 1. The four types of exhalation valves tested in the present study. Valves E, S and W are mushroom style, whereas valve $\mathrm{M}$ has a flat sheet configuration.

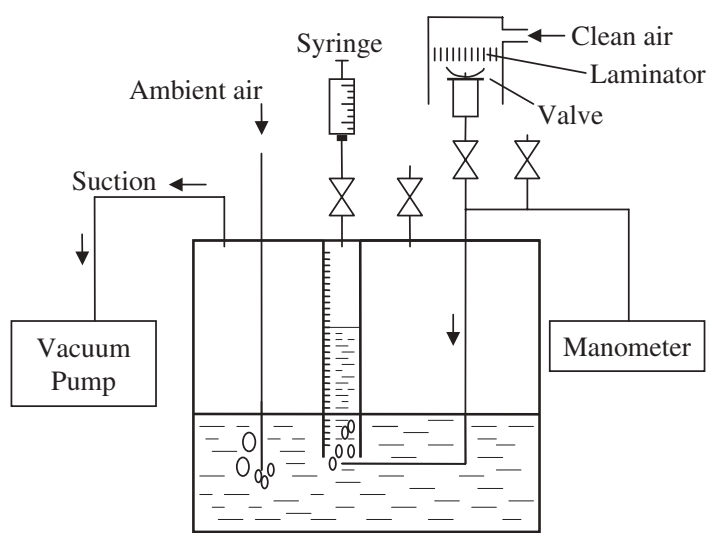

Fig. 2. Schematic diagram of the leakage test meter.

had a flat sheet configuration. Valves $\mathrm{E}, \mathrm{M}$ and $\mathrm{S}$ were made of silicone rubber, whereas the material of valve $\mathrm{W}$ remained unknown.

To perform the leakage test, a bench scale leakage meter was built to measure the leakage rate from the exhalation valve. Figure 2 shows the schematic diagram of the experimental system. A $10 \mathrm{~cm}$ diameter and $25 \mathrm{~cm}$ height transparent acrylic tube was used to construct the main part of the leakage meter. About 1.51 of water was filled in this cylindrical vessel. On the top of this cylindrical test chamber, an exhalation valve holder made of a $3 \mathrm{~cm}$ diameter acrylic tube was built and connected to a stainless tubing that was immersed into the water inside the test chamber. Filtered air at $21 \mathrm{~min}^{-1}$ was applied to protect the tested valves from contamination during the leakage test. 
The air was sucked through the plenum of the test chamber by a vacuum pump to attain the suction pressures for the test. A manometer was used to measure the pressure drop. Seven valves of each brand were tested for leakage rate at pressure drops ranging from 15 to $45 \mathrm{mmH}_{2} \mathrm{O}$ (or extended to $75 \mathrm{mmH}_{2} \mathrm{O}$ for valves $\mathrm{S}$ and $\mathrm{E}$, as will be discussed below). During the experiment, the leakage air from the exhalation valve passed through the stainless tubing and was collected in an air reservoir immersed in water inside the test chamber. The leakage rate of the exhalation valve was defined as the ratio of the measured air leakage volume and the elapsed time. In general, sampling time ranged from several tens of seconds to $10 \mathrm{~min}$ depending on the magnitude of leakage rate. For each test exhalation valve, five measurements were made to obtain a mean leakage rate.

Two types of leaks, i.e. fiber insertion (between valve membrane and valve seat) and arch dent on the valve seat, were used to investigate the effect of leak shape on the characteristic leak flow as a function of pressure drop. Three stainless steel fibers (diameters of 20,50 and $70 \mu \mathrm{m}$ ) were used to create different leak sizes. The arch dents were made by pressing a metal $\operatorname{rod}($ diameter of $6.43 \mathrm{~mm}$ ) on the edge of the valve seat (i.e. contact ring of valve membrane and valve seat) to different depths $(0.09,0.25$ and $0.52 \mathrm{~mm})$.

\section{RESULTS AND DISCUSSION}

Figure 3 shows the effect of pressure drop on the leakage performance of the four brands of exhalation valves. Each leakage data point represents a mean value of five measurements and the error bar denotes $1 \mathrm{SD}$. The data in Fig. 3 are for valves tested as received, without introducing artificial leaks. With increasing suction head, the leakage rate of valves $\mathrm{M}$ and $\mathrm{E}$ increased, whereas the leakage rate through valves $\mathrm{S}$ and $\mathrm{W}$ decreased with increasing pressure drop. The decreasing leakage trend of valves $\mathrm{S}$ and $\mathrm{W}$ indicated that the current method of conducting leakage tests under a constant suction head of $25 \mathrm{mmH}_{2} \mathrm{O}$ might not guarantee better protection when the respirators were used under lower suction heads in practical conditions. In general, the leakage rates of valves $\mathrm{M}$ and $\mathrm{E}$ were higher than those of valves $\mathrm{S}$ and $\mathrm{W}$ at the same suction pressure. Notice that the leakage flow ranges of valves $\mathrm{M}$ and $\mathrm{E}$, and that of $\mathrm{S}$ and $\mathrm{W}$ were 50 and $20 \mathrm{ml} \mathrm{min}^{-1}$, respectively. Most of the valves meet the requirements of the leakage test criteria, i.e. $<30 \mathrm{ml} \mathrm{min}^{-1}$ under $25 \mathrm{mmH}_{2} \mathrm{O}$, except the three E-type valves.

The worst-performing valves of the $\mathrm{S}$ and $\mathrm{E}$ types were tested for extended pressure drop up to $75 \mathrm{mmH}_{2} \mathrm{O}$. Regardless of the differences of the leakage characteristics between the tested exhalation valves, the leakage rate through the valves tended to reach a constant at higher suction pressure for the studied pressure drops of $15-75 \mathrm{mmH}_{2} \mathrm{O}$, as demonstrated in Fig. 4. This phenomenon is similar to the orifice flow effect, but because the pressure drop was far below half of the atmospheric pressure, these constant leakage rates were probably a combined effect of higher pressure drop and shrinkage of the leak hole.

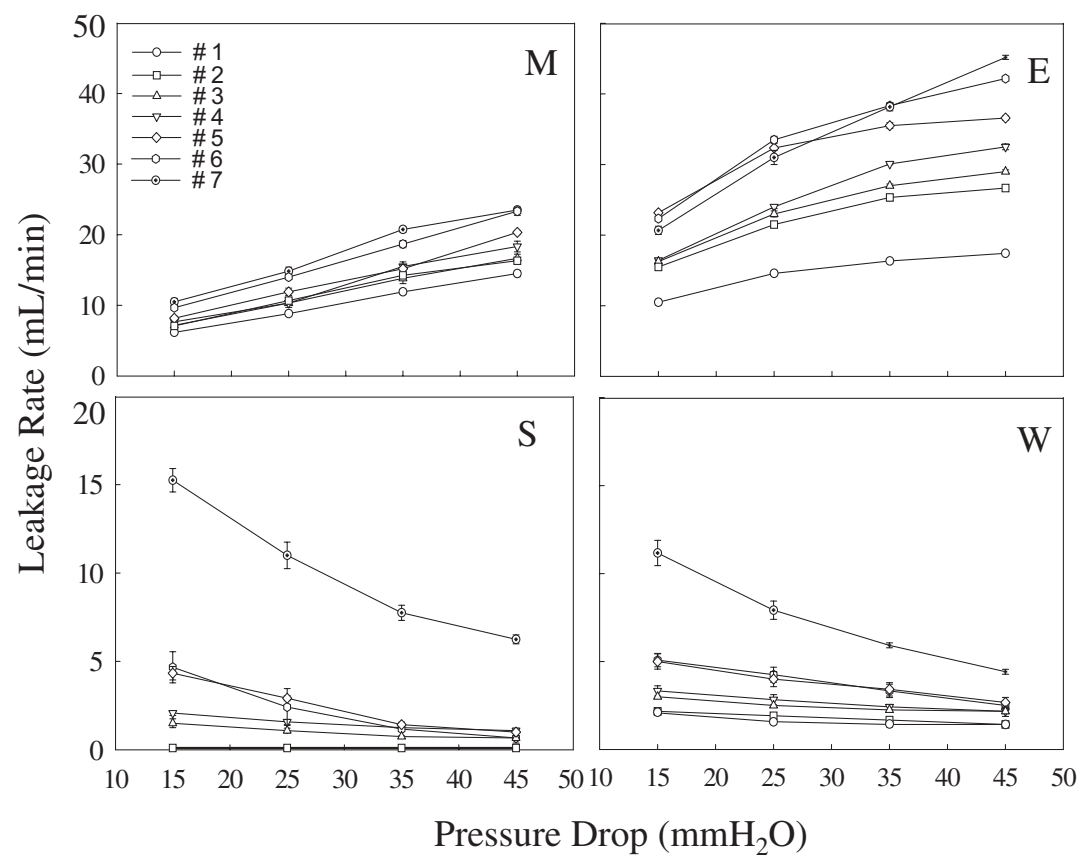

Fig. 3. Leakage characteristics of the four tested exhalation valves. 
In theory, valve leakage can be caused by either a faulty valve membrane or a flawed valve seat, or a combination of both. Another important factor, as discussed below, is poor design. Both components can be perfect, but because of bad design, when subjected to large pressure differences, the membrane distorts on the seat so much that it loses its seal. Of the four brands of exhalation valves, valves $\mathrm{S}$ and $\mathrm{E}$ were chosen to investigate the source of the leakage. For the decreasing trend group, valve seats of the bestand worst-performing valves S1 and S7 were paired with other valve membranes from the same type of valve. As shown in Fig. 5, the leakage rates of seat $S 1$ valves were significantly lower than that of the seat $\mathrm{S} 7$ valves, indicating that it was very likely that seat S7

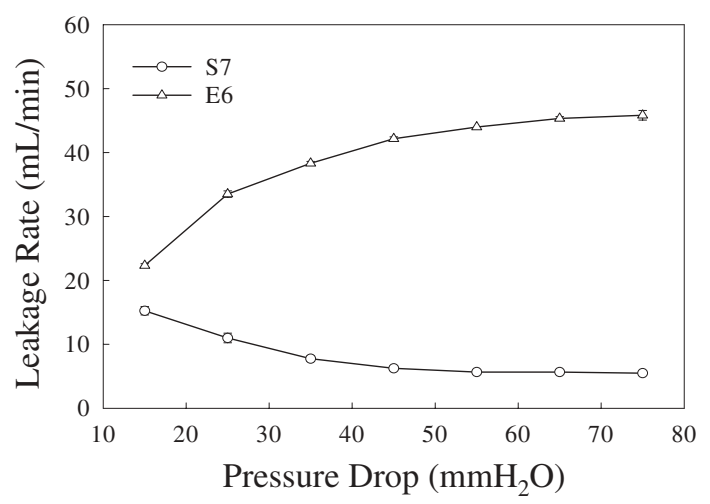

Fig. 4. Leakage characteristics of valves S7 and E6 for extended pressure drop. was defective. While for $E$ valves, the leakage through seat E1 and seat E7 valves had no particular order and was indistinguishable, indicating that the leakage was probably due to defects in both the valve membrane and the valve seat.

Valve $\mathrm{E}$ had a similar design as valves $\mathrm{W}$ and $\mathrm{S}$, but the valve membrane was affixed to the valve seat by placing the membrane (with a hole in the center) on the central rod of the valve seat, while valves $\mathrm{W}$ and $\mathrm{S}$ used a knob to assemble the valve membrane and valve seat. A stopping cap was used in valve $\mathrm{E}$ to fix and prevent the valve membrane from moving up and down, as shown in Fig. 6. The average thickness of the valve membranes was $\sim 0.53 \mathrm{~mm}$. By visual inspection, it was found that in some of the valves the valve membranes were not securely fixed by the cap, either due to the variation in the membrane thickness or because the stopping caps were not pressed hard enough. Figure 6 shows that if $X$, the distance between the surface of valve seat and the bottom edge of the stopping cap $>0.53 \mathrm{~mm}$, the leakage increases with increasing $X$, indicating that the use of a central rod contributed to some extent to the valve leakage. Valve $\mathrm{E}$ also had the highest leakage among the four brands of valves, implying that this valve configuration might not be a good design, perhaps combined with poor manufacturing quality control.

Figure 7 shows the effect of the size of the fiber placed between the membrane and the seat on the leakage rate. Stainless steel fibers, 20, 50 and $70 \mu \mathrm{m}$, in diameter were placed in between the valve membranes and the valve seats of S7 and M1 valves.

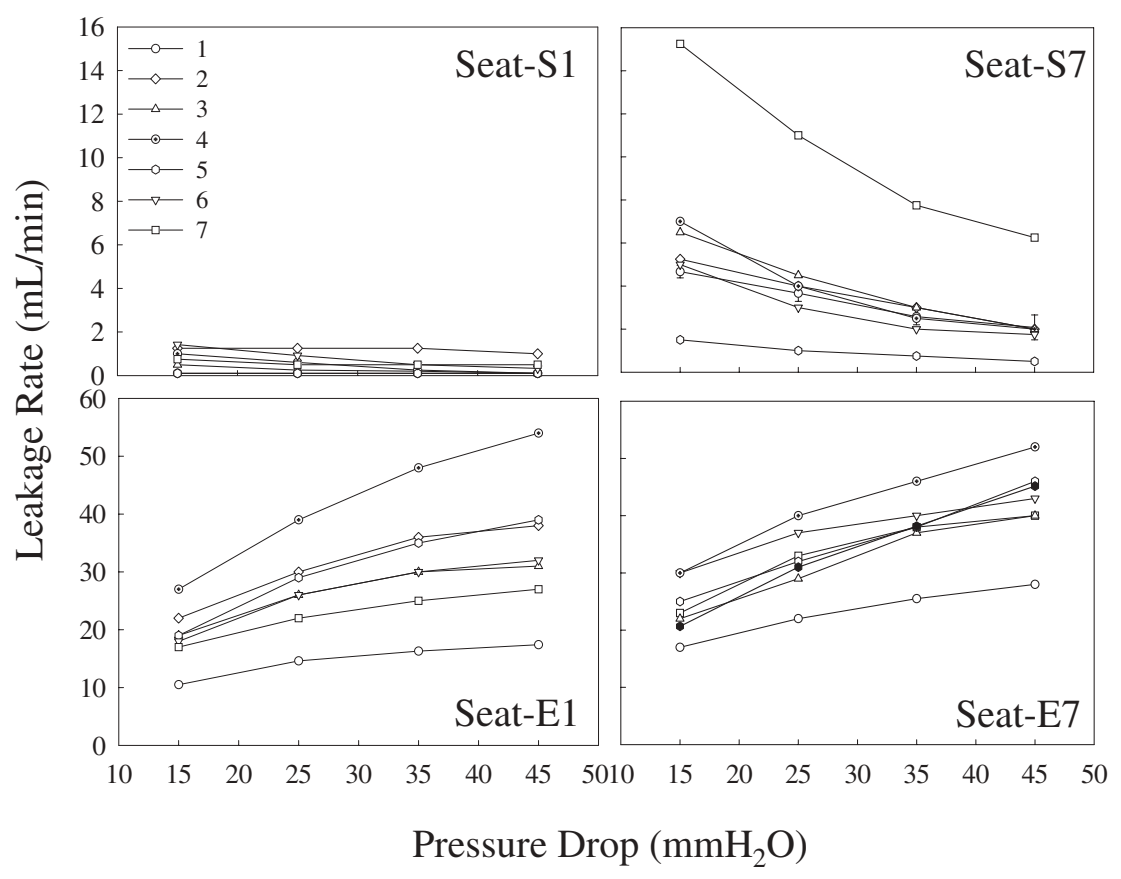

Fig. 5. The sources of leakage. Leakage through the $\mathrm{S}$ valves is apparently due to the flawed valve seats. Leakage through the $\mathrm{E}$ valves is probably a result of both bad valve membranes and flawed valve seats. 


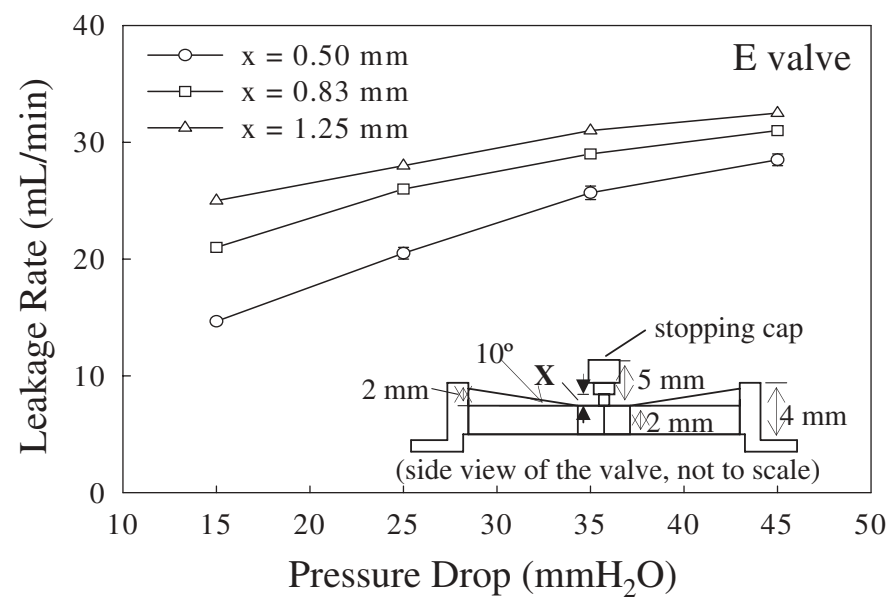

Fig. 6. The effect of valve configuration on the leakage rate. In the $E$ valves, the valve membrane is placed into the center stem on the valve seat in a unique way and the cap is then used to seal the gap.

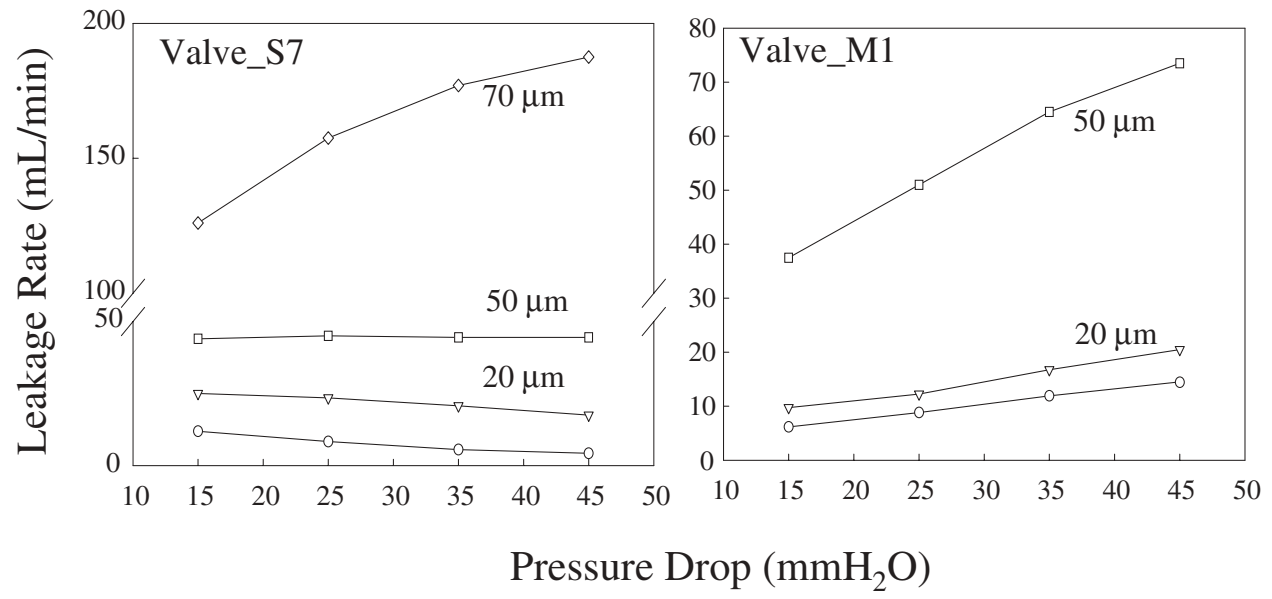

Fig. 7. The effect of fiber size (of insertion type of leak) on the leakage rate.

For both $\mathrm{S}$ and $\mathrm{E}$ valves, the leakage rate increased with increasing fiber diameter, as expected, and increased with increasing pressure drop for most of the cases. A decreasing leakage trend was observed only when the leakage was low, e.g. valve S7 with no fiber insertion and with a $20 \mu \mathrm{m}$ fiber insertion, indicating that once the leak size was small enough, the leak hole might shrink as the vacuum increased. Apparently, this phenomenon was material dependent.

To make an artificial leak on the valve seat, a metal rod was used to press on the rim of the $\mathrm{W}$ valve seat. The diameter of the rod was $6.43 \mathrm{~mm}$, and the depths of three arch-type dents on three separate valve seats were $0.52,0.25$ and $0.09 \mathrm{~mm}$, respectively, as shown in Fig. 8. The leakage rate increased with increasing leak dimensions. This leak-pressure pattern was similar to the fiber-insertion type of leaks, and the decreasing leakage trend against pressure drop would eventually increase with increasing pressure drop, once the leak size reached certain size. For example, for smaller dents of 0.09 and $0.25 \mathrm{~mm}$, the leakage rate decreased with increasing pressure drop, and increased for the larger dent of $0.52 \mathrm{~mm}$.

\section{CONCLUSIONS AND RECOMMENDATIONS}

The leakage rate could increase or decrease with increasing pressure drop, depending on the surface properties of the valve membrane, the valve seat and the size of leak. In this study, valves E and M showed an increasing trend, whereas valves $\mathrm{S}$ and $\mathrm{W}$ showed a decreasing trend. These observations led to the recommendation that the current test regulation on exhalation valves might have to be modified to cover a suitable range of suction heads, in order to assure that the leakage rate did not exceed $30 \mathrm{ml}$ $\min ^{-1}$ under a pressure drop $<25 \mathrm{~mm}$ water gauge.

In this study, the leakage was mainly due to the flawed valve seats, in particular in the S-type valves, 


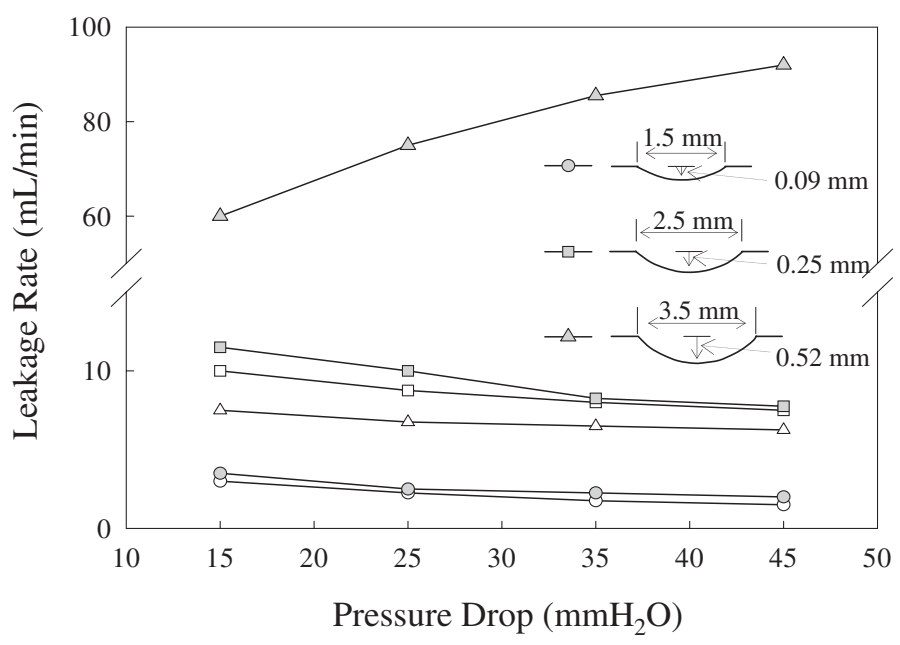

Fig. 8. The effect of arch-dent size on the leakage rate. Open symbols represent the leakage rate of original valves while solid symbols represent those of the corresponding valves with a dent on the seat.

but, for other valves, contribution by the valve membrane could also be significant. The decreasing leakage trend tended to occur when the leak hole was small. The leakage rate might eventually increase with increasing pressure drop if the leak dimension was large enough. As regards the valve design, using a central rod on the valve seat to position the valve membrane and then a stopping cap to secure the membrane was probably not an ideal design, because this approach might introduce extra leakage through the interface between the rod and the membrane hole.

The EN 149 and other European standards are different from 42 CFR part 84 and AS/NZ approaches in that they do not require isolated measurement of exhalation valve leakage. Exhalation valve leakage is assessed as part of the Inward Leakage Test which is included in all European RPE Standards. During inward leakage measurement, the exhalation valve is inherently subjected to a continuously varying pressure drop, and the variations in leakage reported in this study are automatically accounted for. However, these findings on exhalation valve leakage point to the need for a more sophisticated test system and method, apparently not for certification purposes but for better performance of the exhalation valve.

Acknowledgements-This study was partially supported by the National Science Council of Taiwan through grant NSC 90-2320-B-273-005.

\section{REFERENCES}

Bellin P, Hinds WC. (1990) Aerosol penetration through respirator exhalation valves. Am Ind Hyg Assoc J; 51: 555-60.

Brosseau LM. (1998) Aerosol penetration behavior of respirator valves. Am Ind Hyg Assoc J; 59: 173-80.

Chen CC, Willeke K. (1992) Characteristics of face seal leakage in filtering facepieces. Am Ind Hyg Assoc J; 53: 533-9.

Chen CC, Lehtimaki M, Willeke K. (1992) Aerosol penetration through filtering facepieces and cartridges. Am Ind Hyg Assoc J; 53: 566-74.

Chen CC, Lehtimaki M, Willeke K. (1993) Loading and filtration characteristics of filtering facepieces. Am Ind Hyg Assoc J; 54: 51-60.

Hinds WC, Kraske G. (1987) Performance of dust respirators with facial seal leaks: I. Experimental. Am Ind Hyg Assoc J; 48: 836-41.

Nelson DI, Nelson RY, Lawrence CH. (1992) The effect of internal challenge on exhalation valve performance. J Int Soc Resp Protect; 10: 34-46. 